\title{
OBLIQUE WAVE ATTACK ON CUBE AND ROCK ARMOURED RUBBLE MOUND BREAKWATERS
}

\author{
Guido Wolters $^{1}$ and Marcel R.A. van Gent ${ }^{2}$
}

\begin{abstract}
Stability formulae for armour layers of rubble mound breakwaters are usually being applied assuming perpendicular wave attack. Often it is assumed that for oblique wave attack the reduction in damage compared to perpendicular wave attack is small. This seems however a very conservative assumption. Wave basin tests at Deltares provide information to assess the effects of oblique waves on the stability of rock slopes and cube armoured rubble mound breakwaters. This includes cubes in a single layer and cubes in a double layer. The results show that the few available formulae that include wave obliquity underestimate the effects of oblique wave attack; the observed damage to breakwaters with armour layers of rock and cubes is lower and therefore new stability increase factors and mass reduction factors have been developed. The tests were performed for wave directions between perpendicular $\left(0^{\circ}\right)$ and $70^{\circ}$. The results show that large potential savings in diameter and mass can be obtained for large angles of wave obliquity.
\end{abstract}

Keywords: rubble mound breakwaters; breakwater stability; armour layers; oblique waves; rock slopes; cubes

\section{INTRODUCTION}

Stability formulae for armour layers of rubble mound breakwaters are typically based on laboratory experiments in wave flumes. They are therefore generally developed for perpendicular wave attack and do not include the effect of oblique waves. Often it is assumed that for oblique wave attack the reduction in damage compared to perpendicular wave attack is small. This seems however a very conservative assumption. Wave basin tests in various projects indicated that the few available formulae that include wave obliquity are insufficient to describe the observed damage to breakwaters with armour layers of rock and cubes. Therefore, dedicated 3D physical model tests (see also Fig.1) have been performed to assess effects of oblique waves on the stability of rock slopes and cube armoured rubble mound breakwaters.

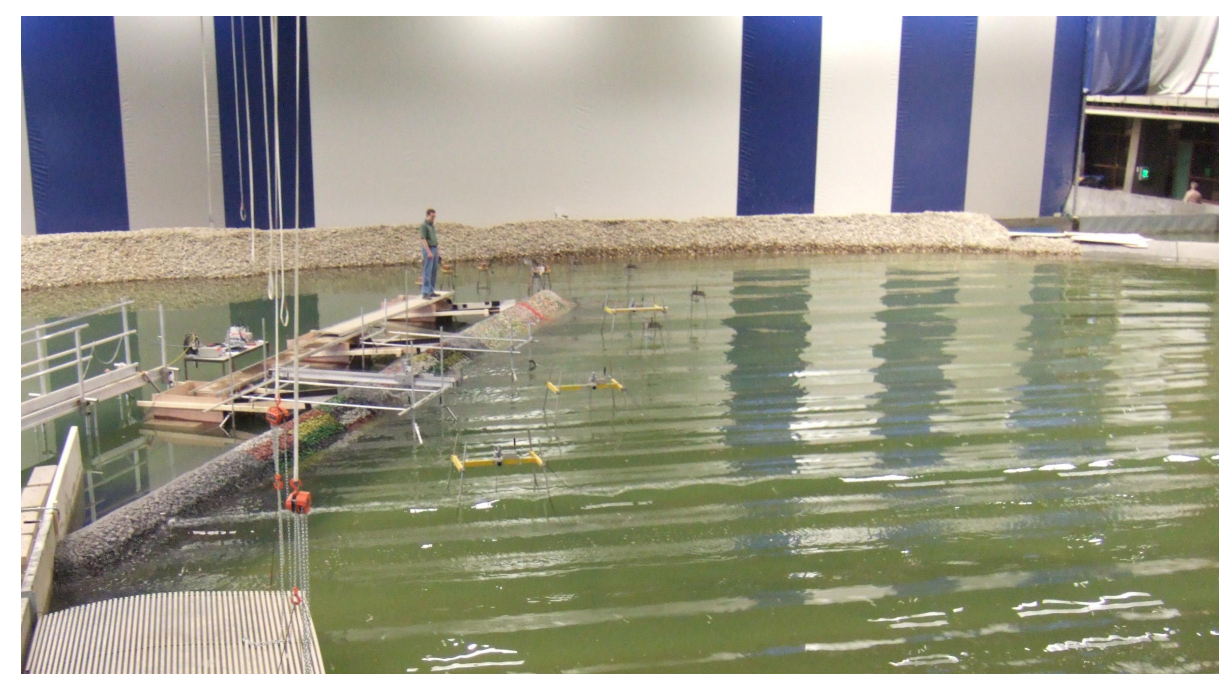

Figure 1. Breakwater in wave basin

\section{PREVIOUS RESEARCH}

In literature information on effects of oblique wave attack on armour layer stability of rubble mound breakwaters is limited. Here, reference is made to the approaches by Galland (1994), Van Gent (2003) and Yu et al. (2002). Whereas the formulae from Galland (1994) and Van Gent (2003) are based on an adaptation of the incident wave height $H_{s}$, the formula from Yu et al. (2002) is based on an adaptation of the stability coefficient $K_{D}$.

\footnotetext{
${ }_{1}^{1}$ Deltares Delft Hydraulics, P.O. Box 177, 2600 MH Delft, The Netherlands, Guido.Wolters@deltares.nl

${ }^{2}$ Deltares Delft Hydraulics, P.O. Box 177, 2600 MH Delft, The Netherlands, Marcel.vanGent@deltares.nl
} 


\section{Galland (1994)}

To take into account the effect of wave obliquity Galland (1994) introduced a new wave height $H_{s, \theta}$ for wave attack under an angle $\theta$ :

$$
H_{S, \theta}=H_{S, \perp} \cdot(\cos \theta)^{X}
$$

where $X$ is the wave obliquity coefficient which depends on the unit under consideration and on the investigated phenomenon (e.g. armour or toe stability, or wave overtopping). Using this new wave height definition it is possible to use stability formulae derived under perpendicular wave attack by including the effect of wave obliquity in the wave height description. The coefficient $X$ for the equivalent wave height $H_{s, \theta}$ can be taken from Table 1:

\begin{tabular}{|c|c|c|c|c|}
\hline & Antifer cube & Tetrapod & Rock & Accropode ${ }^{\circledR}$ \\
\hline Armour stability & 0.6 & 0.3 & 0.25 & 1 \\
\hline Toe stability & 0.6 & 0.4 & 0.6 & 0.4 \\
\hline Overtopping & 1 & 0.6 & $1 / 3$ & 0.75 \\
\hline
\end{tabular}

\section{Van Gent (2003)}

A similar approach as the one by Galland (1994) has also been used by Van Gent (2003) in his tests on the effect of wave obliquity on the stability of rock and cube armoured slopes. The following wave obliquity coefficients $X$ were obtained:

\begin{tabular}{|c|c|c|c|}
\hline & Rock & Single layer cubes & Double layer cubes \\
\hline Armour stability & 1.25 & 2.5 & 1.5 \\
\hline
\end{tabular}

Table 2 shows that the coefficient $X$ for rock as found by Van Gent (2003) is significantly larger than the one published by Galland (1994), indicating that under oblique waves a significant increase in stability can be realised. The given obliquity coefficients of Van Gent (2003) are limited to wave attack angles between $0^{\circ}$ and $45^{\circ}$.

\section{Yu, Liu \& Zhu (2002)}

The study by Yu et al. (2002) is based on the $K_{D}$ based stability formula for rock armour from Hudson (1959). For oblique wave attack Yu et al. (2002) introduced the following expression:

$$
K_{D, \theta}=K_{S} \cdot K_{D} \cdot(\cos \theta)^{-m}
$$

with the directional index $m$ and the directional spreading coefficient $K_{s}$. Directional indices are provided for the following armour layer types: Dolos, Accropode, Hollow-square and rock.

The results of this approach compared well to the results of Van Gent (2003) for rock and wave angles up to $45^{\circ}$. The approach by $\mathrm{Yu}$ et al. (2002) is not further discussed here since the method applied by Galland (1994) and Van Gent (2003) was felt to provide a broader range of applicability (not restricted to available literature on $K_{D}$ values). 


\section{PHYSICAL MODEL TESTS}

\section{General}

Physical model tests on the effect of wave obliquity on armour stability were conducted in a wave basin focussing on the following aspects:

- Wave attack angles of $0^{\circ}, 15^{\circ}, 30^{\circ}, 45^{\circ}, 60^{\circ}$ and $70^{\circ}$.

- Rock and cube armour

- Single and double layer cubes

- Varying cube density

- Armour on a permeable and an impermeable core

The first part of the test series, which dealt with single-layer cube armour and the effect of cube density (on a permeable core) has been discussed in Van Gent (2003). Stability increase factors have been introduced to take into the account the effect of wave obliquity for wave attack angles between $0^{\circ}$ and $45^{\circ}$. In this paper additional focus is laid on the effect of wave obliquity for larger wave angles: between $45^{\circ}$ and $70^{\circ}$.

In total five different types of breakwater armour configurations were studied: Rock armour on a permeable core and on an impermeable core, double layer of cubes on a permeable and on an impermeable core, and a single layer of cubes on a permeable core.

Based on the test results new stability increase factors have been developed. Oblique wave attack is thereby taken into account by introducing an equivalent wave height $H_{s, \theta}$, which is used in the stability formula in place of the $H_{s}$ for perpendicular wave attack (see Eq.1).

\section{Wave basin}

The physical model tests were performed in the Delta basin of Deltares, Delft (50m times 50m). The basin has two multi-directional wave generators $(40 \mathrm{~m}$ and $26.4 \mathrm{~m}$ ), of which only the $26.4 \mathrm{~m}$ wave generator was used for the present study. To prevent reflected waves to re-reflect on the wave paddles, the wave generators are equipped with Active Reflection Compensation (all 180 paddles are equipped with this system). In the present study six wave directions were applied, all with long-crested waves. Second-order wave steering was used to generate realistic shapes of the individual waves ("Stokes waves") and realistic bound long-waves ("wave groups"). The wave board can be steered with standard and non-standard wave spectra as well as specific time series of waves.

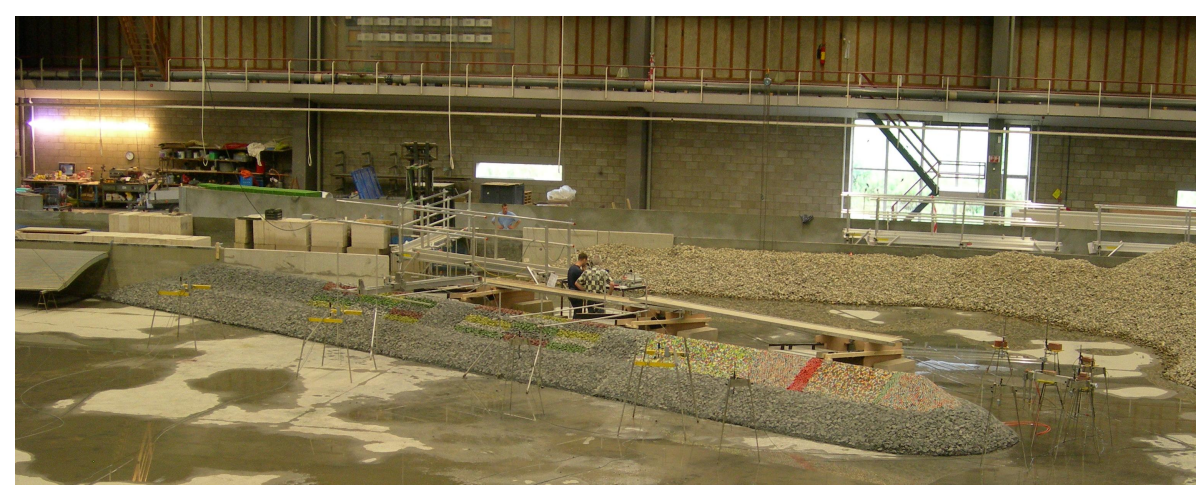

Figure 2. Overview of breakwater model in wave basin.

\section{Test set-up}

The set-up of the 3D breakwater model tests is shown in Fig.2 and Fig.3. A horizontal bathymetry was used in the tests. A spending beach was placed around the basin boundaries to dissipate the transmitted waves.

Three trunk sections of the breakwater model (see Fig.3) are discussed here:

- S1: Rock on a permeable core.

- S2: Rock on an impermeable core.

- S3: Cubes in double layer on an impermeable core. 
Material specifications are given in Table 3. The armour material was placed directly on top of the core material for Section S1. For the Sections S2 and S3 a filter layer was used above an impermeable (concrete) core. For the impermeable test sections the same filter material was used as for the core of the permeable rock sections. The employed armour thickness was $2 D_{n 50}$ (rock and double layer cubes) with a filter layer thickness of $2 D_{n 50}$ (rock) for the section with an impermeable core. Besides each test section (with a width of $1 \mathrm{~m}$ ) $2.5 \mathrm{~m}$ long dummy sections with properly scaled material were used to guarantee that during oblique wave attack the attacking waves are correctly simulated on the slope before they reach the actual test section.

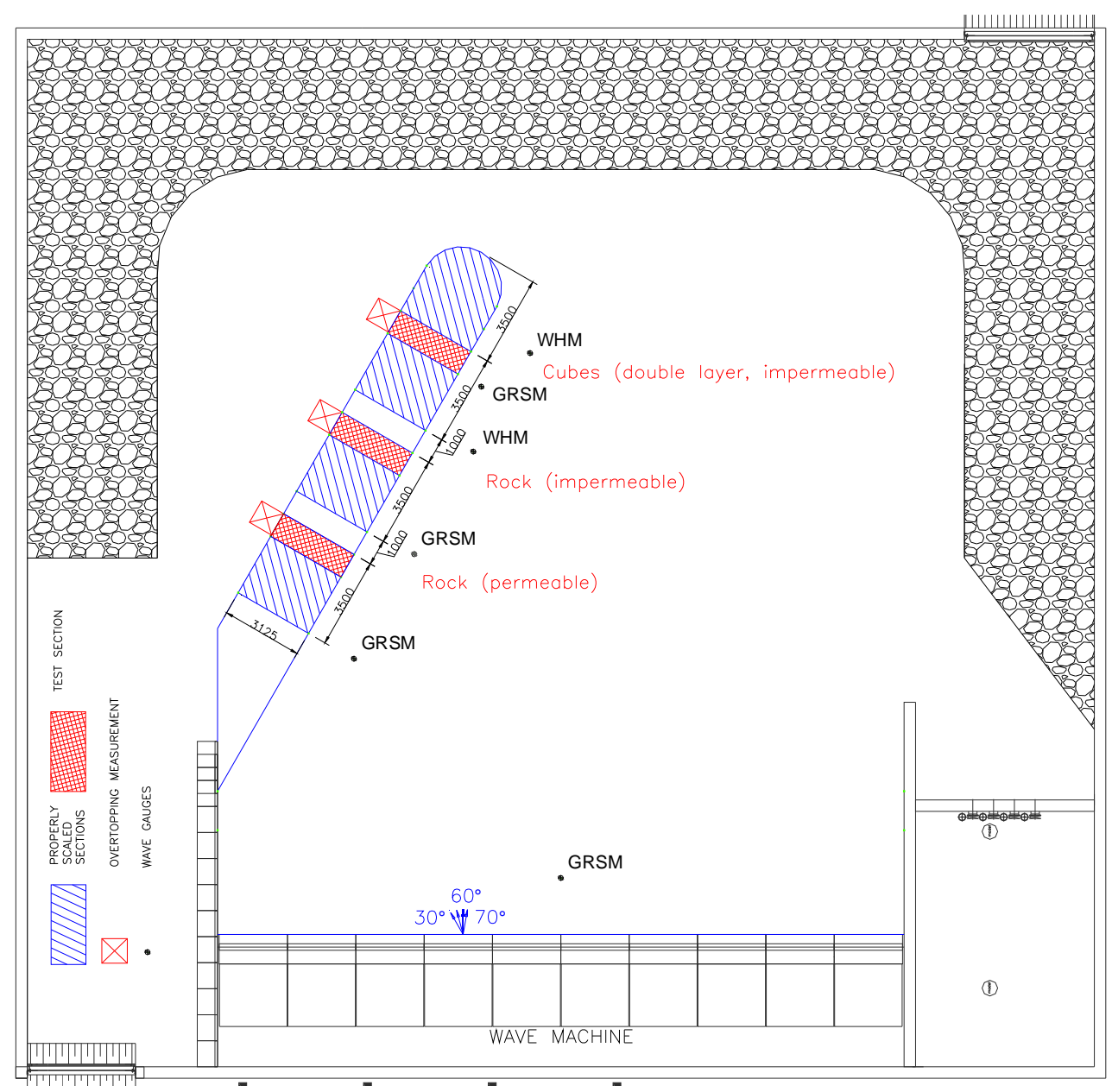

Figure 3. Set-up of breakwater in wave basin.

\begin{tabular}{|l|c|c|c|}
\hline \multicolumn{4}{|l|}{ Table 3. Materials. } \\
\hline & Density $\left[\mathrm{kg} / \mathrm{m}^{3}\right]$ & $D_{n 15} / D_{n 85}[-]$ & $M_{85} / M_{15}[-]$ \\
\hline Core / Filter & 2700 & 0.63 & 3.3 \\
Rock Armour & 2670 & 0.80 & 2 \\
Cubes & 2350 & - & - \\
\hline
\end{tabular}

Since the expected damage for the available cubes and typical model wave heights $\left(H_{s} \leq 0.2 \mathrm{~m}\right)$ was low, it was decided to test cube stability only for a double cube layer with an impermeable core, which was expected to increase the damage to the armour layer compared to a double layer with a permeable core such that damage could be obtained even for large wave obliquity. 
A regular placement of the cube double layer was chosen. The placement is similar to the 'double pyramid' placement method (see Frens et al., 2008) but without any upward block shift between the upper and lower layer.

The actually achieved armour layer porosity $n_{v}$ and the packing density $\Phi=n \cdot k_{t} \cdot\left(1-n_{v}\right)$, where $k_{t}=1.1$ refers to the layer coefficient and $n=2$ to the number of layers, for the individual cube sections are given in Table 4.

\begin{tabular}{|c|c|c|}
\hline \multicolumn{3}{|c|}{ Table 4. Porosity and packing density of cube test sections. } \\
\hline Angle $\left[^{\circ}\right]$ & Porosity $[-]$ & Packing density $[-]$ \\
\hline $45^{\circ}$ & 0.38 & 1.36 \\
$60^{\circ}$ & 0.36 & 1.40 \\
$70^{\circ}$ & 0.37 & 1.38 \\
\hline Average & 0.37 & 1.38 \\
\hline
\end{tabular}

\section{Recording of damage}

The damage was recorded by taking digital overlay photographs before and after each test, by counting the number of stones and cubes that were displaced more than 1 unit diameter (damage number $N_{O D}$ ) and by means of a mechanical profiler to assess the damage level $S$ for rock sections.

Between individual tests runs with constant wave direction the structure was not repaired (cumulative damage). Only after completion of each test series (constant wave direction) the armour layer and toe were reconstructed.

\section{Test programme}

The characteristics of the test programme are given in Table 5:

\begin{tabular}{|l|c|c|}
\hline \multicolumn{2}{|l|}{ Table 5. Characteristics of test series. } \\
\hline Description & Parameter & Range \\
\hline angle of wave attack & $\theta$ & $45^{\circ}, 60^{\circ}, 70^{\circ}$ \\
wave steepness & $S_{o p}$ & 0.04 \\
$\begin{array}{l}\text { relative water depth at } \\
\text { the structure }\end{array}$ & $h_{s} / H_{m 0}$ & $2.7-13.3$ \\
$\begin{array}{l}\text { relative freeboard } \\
\text { crest width (in front of } \\
\text { crest element) } \\
\text { slope angle }\end{array}$ & $R_{c} / H_{m 0}$ & $1.1-5.6$ \\
\hline
\end{tabular}

The tests were conducted with a test duration of 1000 waves, a JONSWAP wave spectrum (peak enhancement factor $\gamma=3.3$ ) and long-crested waves.

\section{TEST RESULTS AND ANALYSIS}

\section{Damage initiation and failure based on stability number}

In this investigation initial damage and failure for the various wave directions occurred at the values of the stability number $\left(N_{s}=H_{s} / \Delta D_{n 50}\right)$ as shown in Table 6.

Table 6 shows a consistent increase in $N_{s}$ for increasing wave obliquity in rock and cube armoured slopes. The table is valid for the investigated conditions of a 1:1.5 breakwater slope.

The damage initiation for a breakwater armour consisting of a double layer of cubes and perpendicular wave attack was found to occur at similar $N_{s}$ values than expected by the Rock Manual (2007), that is at $H_{s} / \Delta D=2-2.4$. For larger angles of wave obliquity damage initiation occurs at significantly higher wave heights. The initial damage for armour stone (perpendicular wave attack) was found to occur at $N_{s}$ values of $H_{s} / \Delta D_{n 50}<1.1$. 


\begin{tabular}{|c|c|c|c|c|c|c|c|c|}
\hline \multirow[t]{3}{*}{ Angle of wave attack } & \multicolumn{4}{|c|}{ Initial damage $\left(N_{s}\right)$} & \multicolumn{4}{|c|}{ Failure $\left(N_{s}\right)$} \\
\hline & \multicolumn{2}{|c|}{ Rock } & \multicolumn{2}{|c|}{ Cubes } & \multicolumn{2}{|c|}{ Rock } & \multicolumn{2}{|c|}{ Cubes } \\
\hline & Perm & $\operatorname{Imp}$ & Perm & $\operatorname{Imp}$ & Perm & $\operatorname{Imp}$ & Perm & $\operatorname{Imp}$ \\
\hline Perpendicular* & $<1.1$ & - & $>2.1$ & - & 1.6 & - & 3.0 & - \\
\hline $15^{\circ *}$ & $<1.1$ & - & 2.5 & - & $<1.6$ & - & 3.1 & - \\
\hline $30^{\circ}$ * & 1.3 & - & 3.5 & - & $>1.7$ & - & $>3.5$ & - \\
\hline $45^{\circ}$ & $1.2-1.5$ & $<1.5$ & $>3.3$ & $>2.7$ & 2.2 & $>1.5$ & 4.5 & 3.9 \\
\hline $60^{\circ}$ & $<2.2$ & $>1.6$ & - & 3.8 & 3.1 & $>2.2$ & - & $>3.8$ \\
\hline $70^{\circ}$ & $>2.2$ & 2.2 & - & 5.6 & 3.5 & $>3.5$ & - & 6.7 \\
\hline
\end{tabular}

\section{Wave obliquity coefficients for rock}

The calculated wave obliquity coefficients $X$ (wave attack angles $0^{\circ}-70^{\circ}$, including data from Van Gent, 2003) are summarized in Table 7 for all investigated conditions.

\begin{tabular}{|c|c|c|c|}
\hline Wave obliquity coefficient & Rock & Single layer cubes & Double layer cubes \\
\hline Permeable core & 1.05 & $2.5^{\star}$ & $1.5^{*}$ \\
\hline Impermeable core & 1.05 & - & 0.95 \\
\hline
\end{tabular}

The wave obliquity coefficients in Table 7 are based on the damage number $N_{O D}$. The same stability trend was found for rock slopes on a permeable core and on an impermeable core for wave attack angles up to $60^{\circ}$ with a wave obliquity coefficient of $X=1.05$. This is somewhat lower than the value for rock slopes with a permeable core $(X=1.25)$ as calibrated by Van Gent (2003) based on the wave angles between $0^{\circ}$ and $45^{\circ}$ only. For structures on an impermeable core the obliquity factor was seen to hold even for higher degrees of wave obliquity $\left(70^{\circ}\right)$. The results of the rock slope with a permeable core are somewhat in doubt for the wave angle of $70^{\circ}$, since they might have been influenced by model effects (guide wall influence). Therefore, in light of the ongoing exponential trends observed for all other investigated sections, no change in obliquity coefficient is proposed.

Based on the derived wave obliquity coefficients the stability increase (factor $f$ ) for wave obliquity can be calculated (see Fig.4 and Fig.5). It is based on the stability number $N_{s}=H_{s} / \Delta D$ and defined as:

$$
f=\frac{N_{S, \perp}}{N_{S, \theta}}
$$

\section{Wave obliquity coefficients for cubes}

The obliquity coefficient of $X=1.5$ as derived from Van Gent (2003) for cubes with a permeable core could not be verified for larger wave angles in these new tests since, due to the test set-up, only cube armour layers with an impermeable core could be tested. The obliquity coefficient as found for structures with an impermeable core was $X=0.95$. The damage for the cube layers on an impermeable core is thus significantly less influenced by the angle of wave attack than predicted for cube layers on a permeable core.

The tests have shown that the cube section S3 (with an impermeable core) tends to fail swiftly after initial damage has occurred. Although initial damage occurred later compared to the rock sections, damage progression was much faster so that the cube armour failed before the rock sections (S1 and S2). The only exceptions were the tests with wave obliquity of $70^{\circ}$. In this case the cube armour showed initial damage only after the last test with the highest wave height (no failure). This effect of progressive damage is even more pronounced for single layer cube armour, see Fig.6 and Van Gent (2003). 


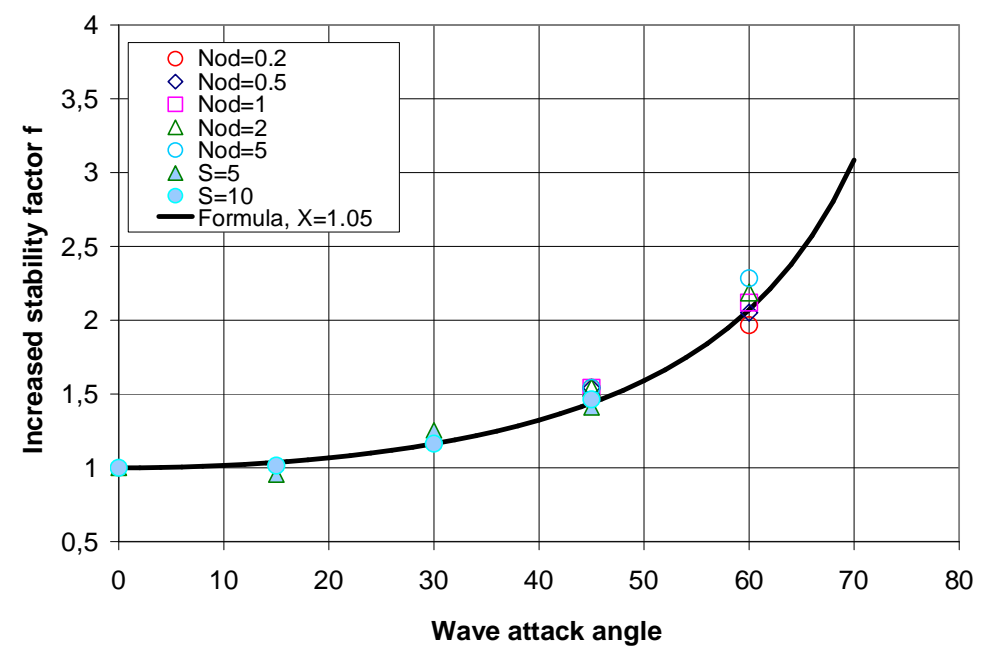

Figure 4. Increased stability factors $f$ for rock slopes with a permeable core $\left(N_{O D}\right)$.

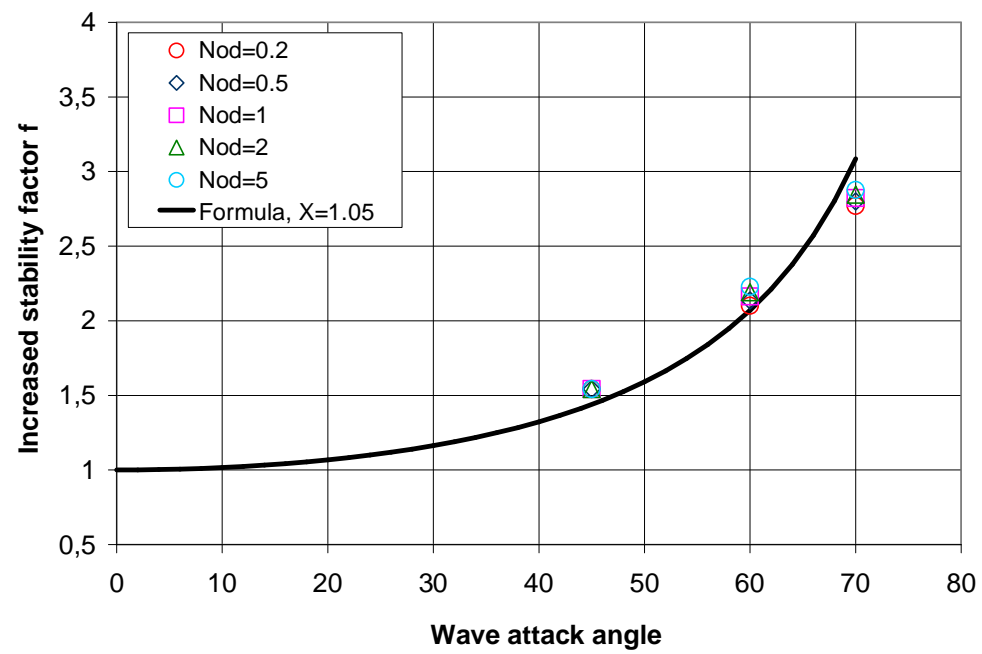

Figure 5. Increased stability factors $f$ for rock slopes with an impermeable core $\left(N_{O D}\right)$.

\section{Summary of results}

Fig. 8 shows a summary of the obtained stability trends for rock slopes (equal for structures with an impermeable core and a permeable core), cubes in a double armour layer with an impermeable and permeable core, and cubes in a single layer with a permeable core.

\section{Practical aspects}

Using the wave obliquity coefficients from the previous paragraphs the potential savings in mass and stone diameter can be calculated based on the following relationships:

$$
D_{n 50, \theta}=D_{n 50, \perp} \cdot \cos \theta^{x}, \quad M_{n 50, \theta} \sim\left(D_{n 50, \perp} \cdot \cos \theta^{x}\right)^{3}
$$

The potential savings in stone diameter and mass are given in Table 8 and 9 for varying angles of wave obliquity. Table 8 and 9 show that potential savings in mass of up to $90 \%$ can be realized for a wave obliquity of $60^{\circ}$ (which corresponds to a $50 \%$ reduction in stone diameter). The test results indicate that even a further decrease in mass is possible for wave obliquities up to $70^{\circ}$ (up to $75 \%$ reduction in stone diameter). This needs however careful consideration in practice, since small variations in wave direction or wave climate can otherwise lead to sudden failure of the structure. 


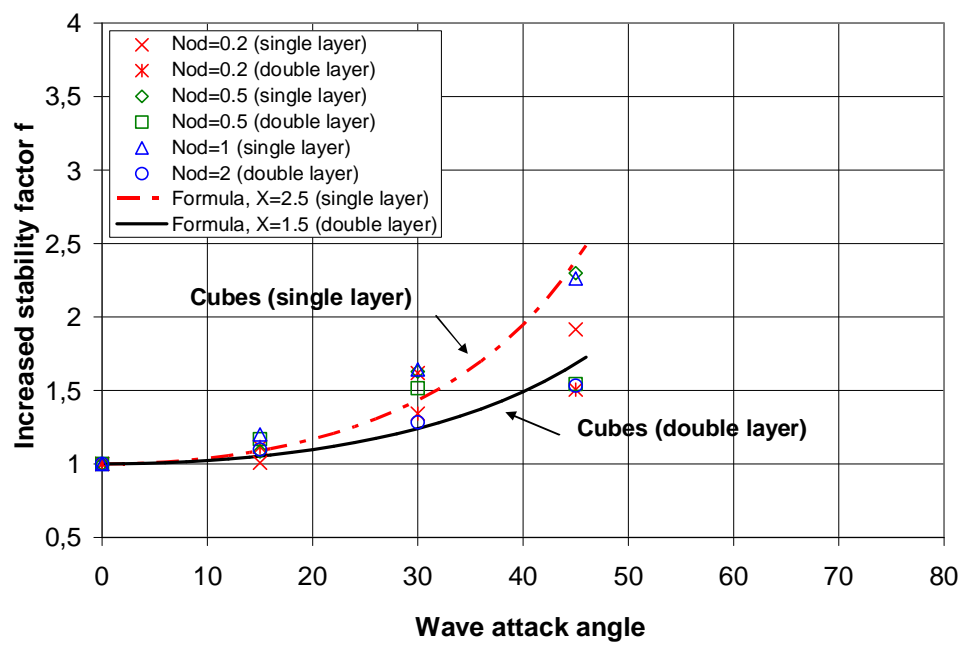

Figure 6. Increased stability factors $f$ for cubes on a permeable core $\left(N_{O D}\right)$.

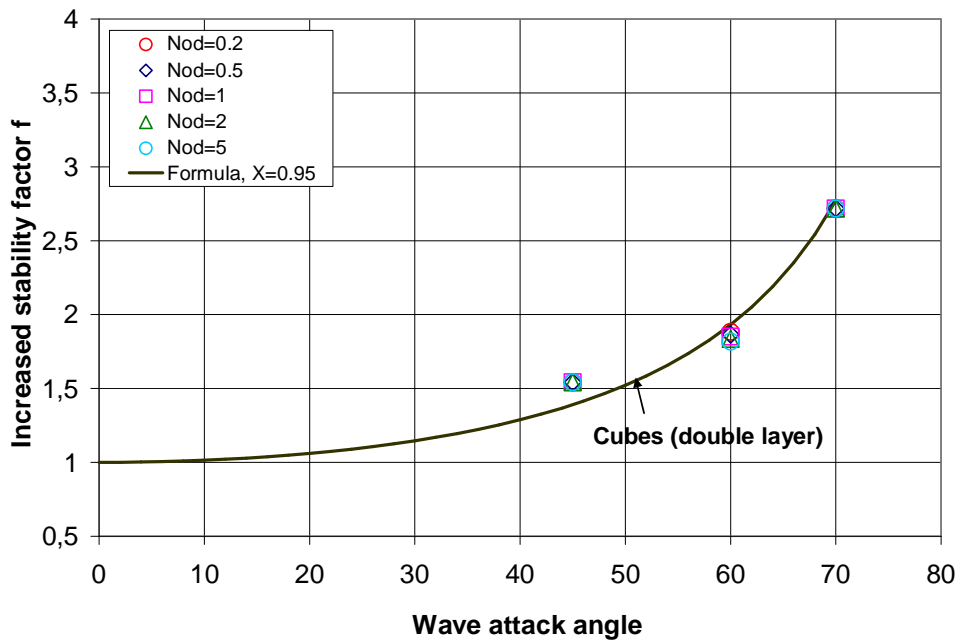

Figure 7. Increased stability factors $f$ for cubes on an impermeable core $\left(N_{O D}\right)$.

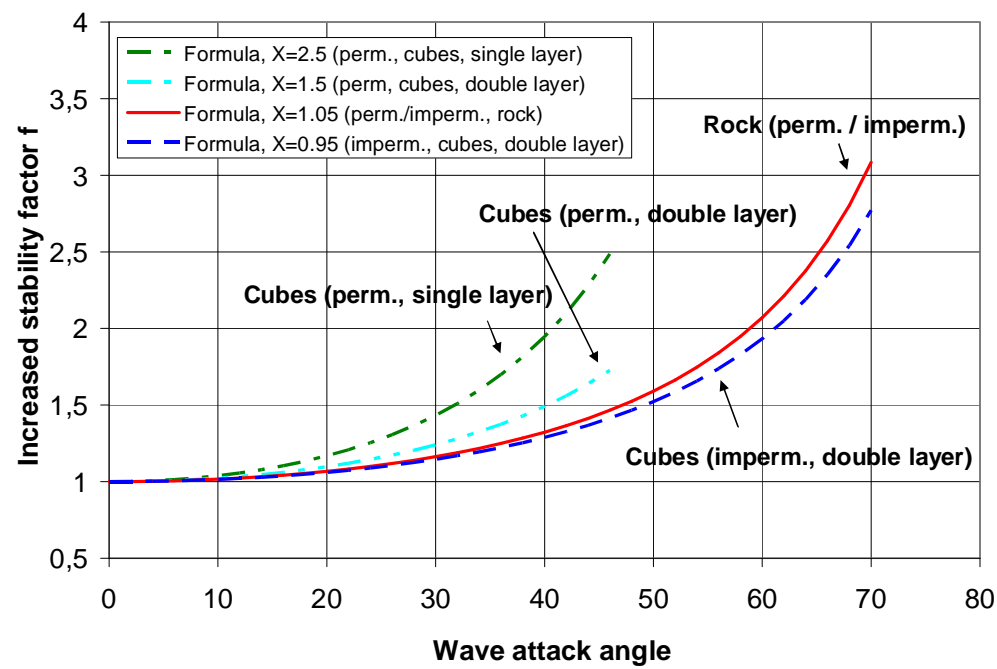

Figure 8. Summary of results for rock and cubes $\left(N_{O D}\right)$. 


\begin{tabular}{|c|c|c|c|c|}
\hline & $\begin{array}{c}\text { Wave } \\
\text { obliquity }\left({ }^{\circ}\right)\end{array}$ & Rock & $\begin{array}{l}\text { Single layer } \\
\text { cubes }\end{array}$ & $\begin{array}{l}\text { Double layer } \\
\text { cubes }\end{array}$ \\
\hline \multirow{6}{*}{ Permeable core } & 0 & 1.00 & 1.00 & 1.00 \\
\hline & 15 & 0.96 & 0.92 & 0.95 \\
\hline & 30 & 0.86 & 0.70 & 0.81 \\
\hline & 45 & 0.69 & 0.42 & 0.59 \\
\hline & 60 & 0.48 & 0.18 & 0.35 \\
\hline & 70 & 0.32 & $<0.10$ & 0.20 \\
\hline \multirow{6}{*}{ Impermeable core } & 0 & 1.00 & & 1.00 \\
\hline & 15 & 0.96 & & 0.97 \\
\hline & 30 & 0.86 & & 0.87 \\
\hline & 45 & 0.69 & & 0.72 \\
\hline & 60 & 0.48 & & 0.52 \\
\hline & 70 & 0.32 & & 0.36 \\
\hline
\end{tabular}

Table 9. Potential savings in mass (fraction compared to perpendicular wave attack).

\begin{tabular}{|l|c|c|c|c|}
\hline & $\begin{array}{c}\text { Wave } \\
\text { obliquity }\left(^{\circ}\right)\end{array}$ & Rock & $\begin{array}{c}\text { Single layer } \\
\text { cubes }\end{array}$ & $\begin{array}{c}\text { Double layer } \\
\text { cubes }\end{array}$ \\
\hline \multirow{4}{*}{ Permeable core } & 0 & 1.00 & 1.00 & 1.00 \\
& 15 & 0.90 & 0.77 & 0.86 \\
& 30 & 0.64 & 0.34 & 0.52 \\
& 45 & 0.34 & $<0.10$ & 0.21 \\
& 60 & 0.11 & $<0.10$ & $<0.10$ \\
& 70 & $<0.10$ & $<0.10$ & $<0.10$ \\
\hline \multirow{3}{*}{ Impermeable core } & 0 & 1.00 & - & 1.00 \\
& 15 & 0.90 & - & 0.91 \\
& 30 & 0.64 & - & 0.66 \\
& 45 & 0.34 & - & 0.37 \\
& 60 & 0.11 & - & 0.14 \\
& 70 & $<0.10$ & - & $<0.10$ \\
\hline
\end{tabular}

It should also be mentioned that safety considerations are not included in Tables 8 and 9 . Furthermore, no test results are available for even larger angles such as $90^{\circ}$. Since other phenomena may play a role for waves that approach structures under an angle of $90^{\circ}$, it is unknown whether such waves would lead to a further reduction or to an increase in damage compared to the effects of oblique waves studied here.

\section{CONCLUSIONS}

The objective of this research study was to assess the effects of oblique wave attack on the armour stability of a typical rubble mound breakwater. The study focussed on armour layers of rock and cubes on an impermeable or permeable core. This includes cubes in a single layer and cubes in a double layer. The research extends earlier research performed by Galland (1994) and Van Gent (2003).

The performed tests show that the few available formulae that include wave obliquity underestimate the effects of oblique wave attack; the observed damage to breakwaters with armour layers of rock and cubes is lower and therefore new stability increase factors and mass reduction factors have been developed. The results show that large potential savings in diameter and mass can 
be realised for large angles of wave obliquity. The tests were performed for wave directions between perpendicular $\left(0^{\circ}\right)$ and $70^{\circ}$ and for a $1: 1.5$ slope.

It is recommended to analyse whether the observed stability increase factors are also valid for more gentle slopes (e.g. 1:2 or 1:4) and whether waves that approach structures under an even larger angle such as $90^{\circ}$, lead to a further reduction or to an increase in damage compared to the effects of oblique waves studied here.

\section{REFERENCES}

CEM. 2005. Coastal Engineering Manual, Part VI, US Army Corps of Engineers, Washington, D.C.

Frens, A.B., M.R.A. van Gent and J. Olthof. 2008. Placement methods for antifer armour units, World Scientific, Proc. ICCE 2008, Vol.4, pp.3337-3345.

Galland, J.-C. 1994. Rubble mound breakwater stability under oblique waves: and experimental study, Proc. Coastal Engineering 1994, 1061-1074.

Hudson, R.Y. 1959. Laboratory investigations of rubble mound breakwaters, J. Waterways \& Harbors Div, Am Soc Civ Engrs, vol 85, no WW3, Paper no 2171, 93-121.

Rock Manual. 2007. The Rock Manual. The use of rock in hydraulic engineering, CIRIA, CUR, CETMEF, $2^{\text {nd }}$ edition, C683, CIRIA, London.

Van Gent, M.R.A. 2003. Recent developments in the conceptual design of rubble mound breakwaters, COPEDEC VI, Colombo, Sri Lanka.

Yu, Y.-X., S.-X. Liu, C.-H. Zhu. 2002. Stability of armour units on rubble mound breakwater under multi-directional waves, Coastal Engineering Journal, Vol. 44, No. 2, 179-201. 